\title{
Design of All-reflective Space- borne 1-m Aperture Solar Optical Telescope
}

Y. Suematsu, H. Hara, Y. Katsukawa, R. Kano National Astronomical Observatory of Japan

T. Shimizu ISAS/JAXA

K. Ichimoto Hida Observatory, Kyoto University 


\section{Highly dynamic solar chromosphere}

- Chromosphere: High cadence imaging of spicules

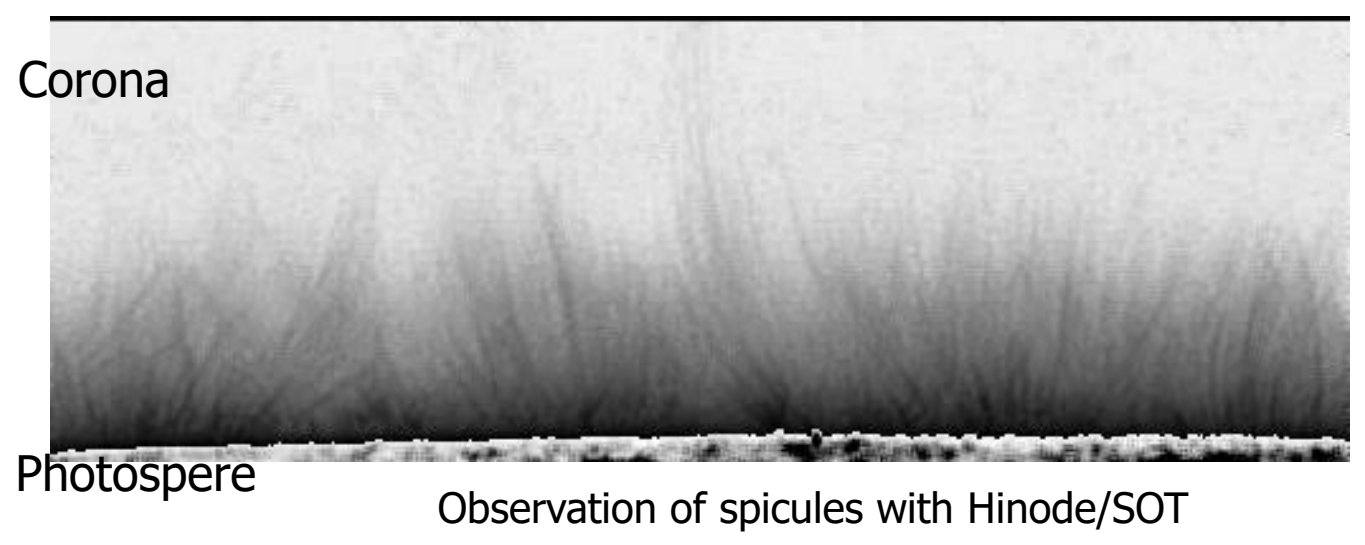

\section{Impliation of Hinode obs.}

Wave energy flux estimate from apparent lateral motion and oscillation

$2 \times 10^{5} \sim 1 \times 10^{6} \mathrm{erg} \mathrm{cm}^{-2} \mathrm{~s}^{-1}$

- lack of spatial distribution of energy flux - not applicable for AR plage

$\Rightarrow$ Cannot specify heating

mechanism

- Subject: Quantitative measurements of Poynting flux ExB $\Rightarrow$ Measure chromospheric magnetic filed $(\sim 20 \mathrm{G})$ - velocity fields $(\sim 3 \mathrm{~km} / \mathrm{s})$

- Subject: Formation mechanism of spicules $\Rightarrow$ Connect photospheric and chromospheric magnetic fields

$\Rightarrow$ resolve fundamental structure in the photosphere and chromosphere $\sim 0.1^{\prime \prime}$ 


\section{Spicule formation and their effect on Corona}

Mysterious spicule
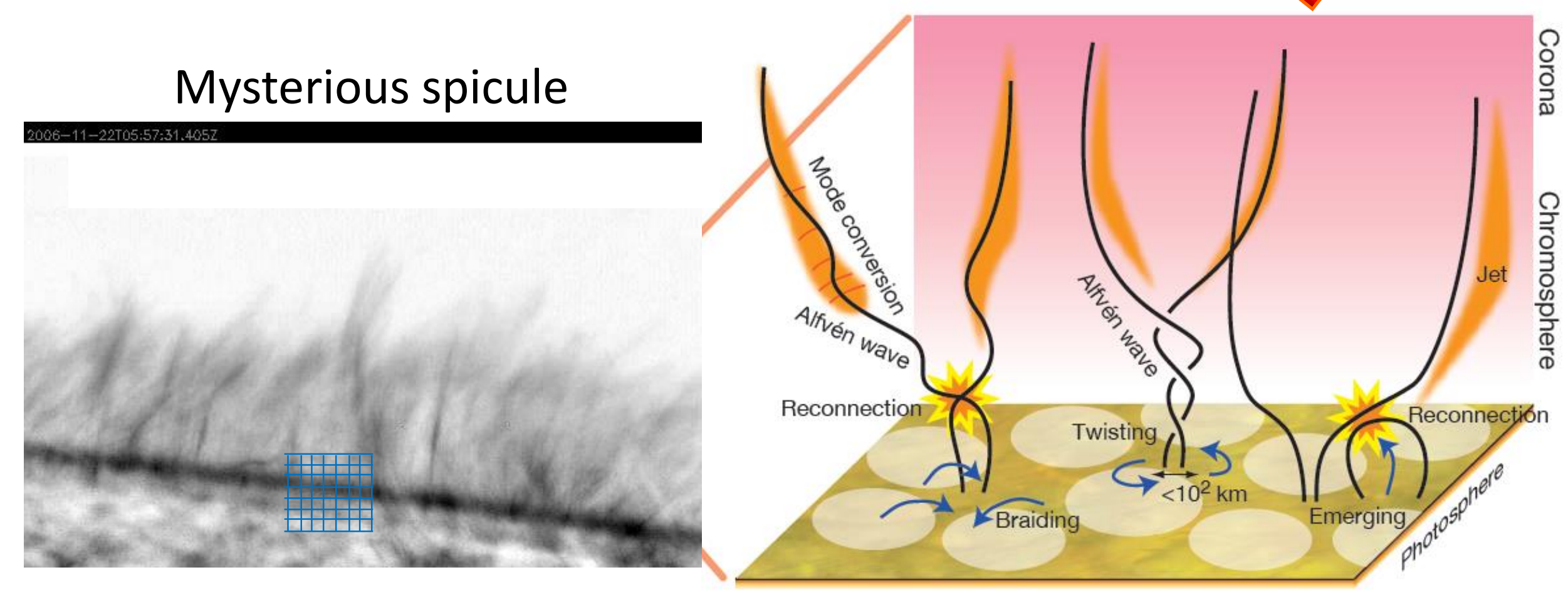

SUVIT will see fine scale connection between photo. \& chrom., current sheets, mag.reconnection, shock,,

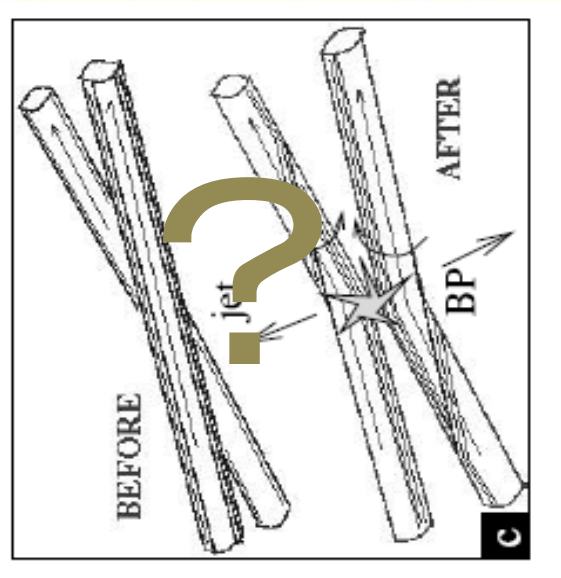

What is going on at the foot point of spicules?

- Component reconnection?

- Vortex and twist?

- Emerging flux? 


\section{Mechanism of Flares and Eruptions}

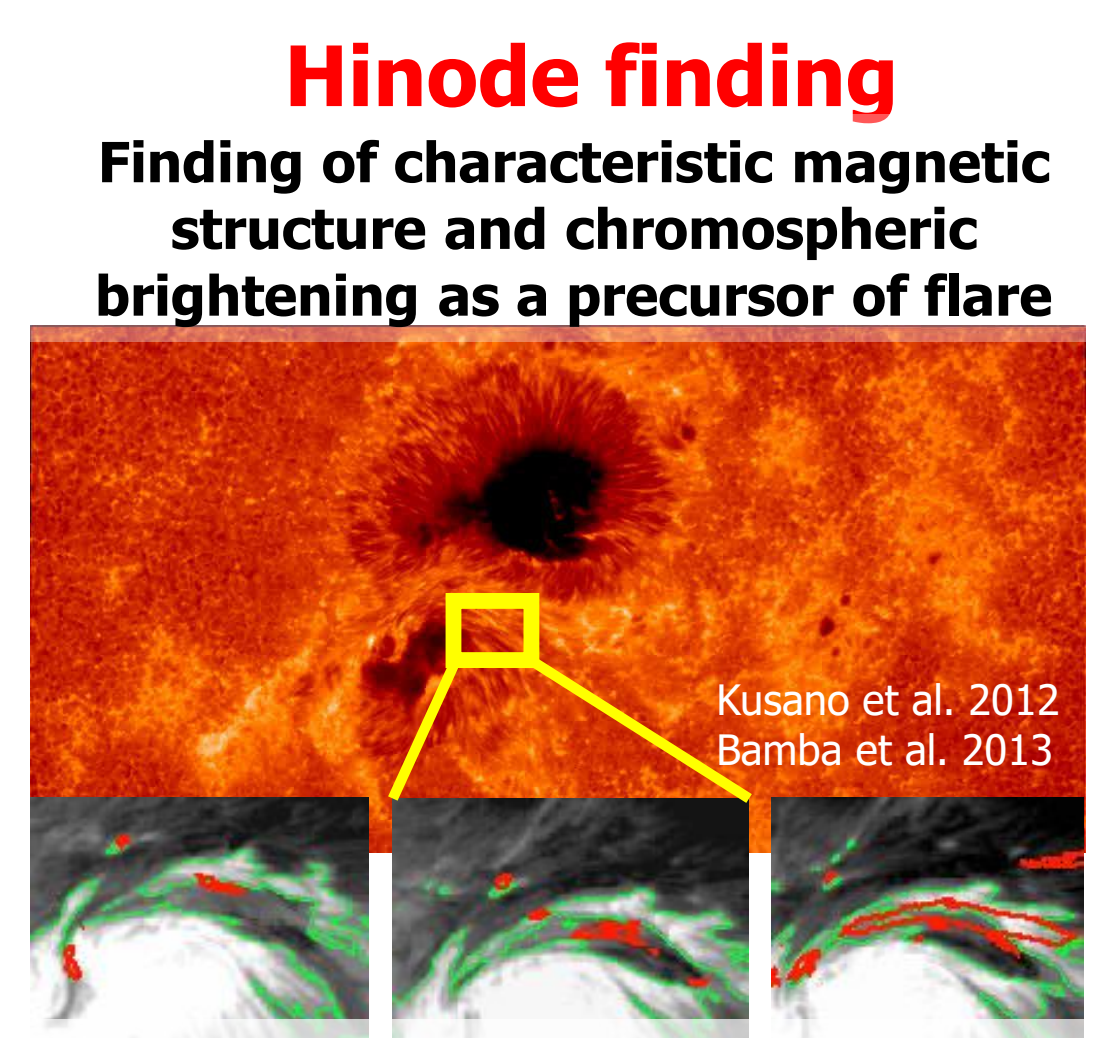

Black and white: $\mathrm{B}$ red contour: chromo brightening

\section{Implication from Hinode finding}

- Importance of multi-scale structure at the onset

- Probable triggering by small-scale mag. strucure in the chromosphere or lower corona
Subject: resolve small-scale magnetic structure triggering explosion $\Rightarrow$ precise obs. of photosperic and chromospheric magnetic stretsures

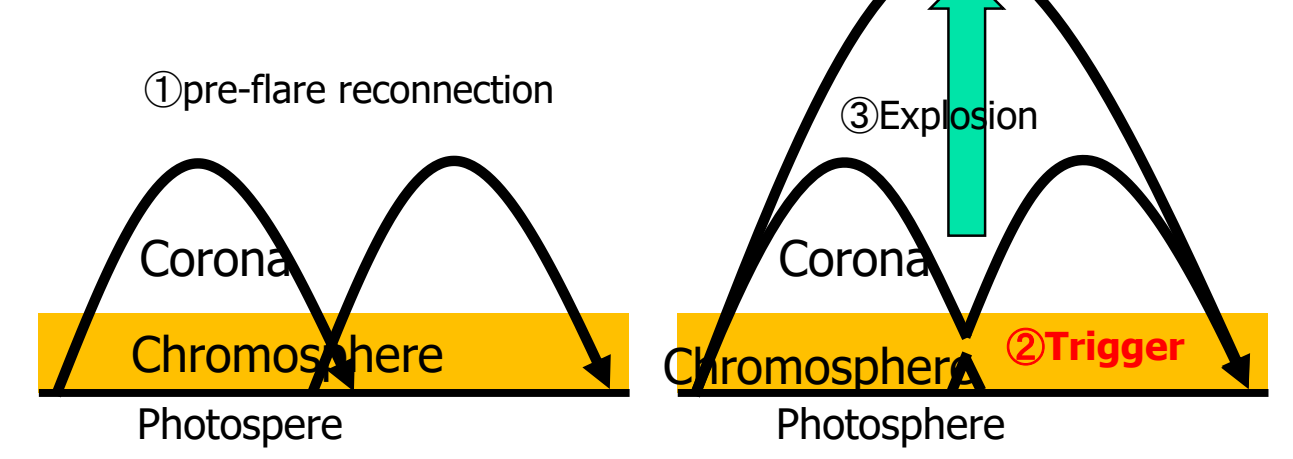

Subject: resolve mechanism of energy accumulation and destabilization (Reconstruction of 3D magnetic structure with help of chromospheric magnetic measurements

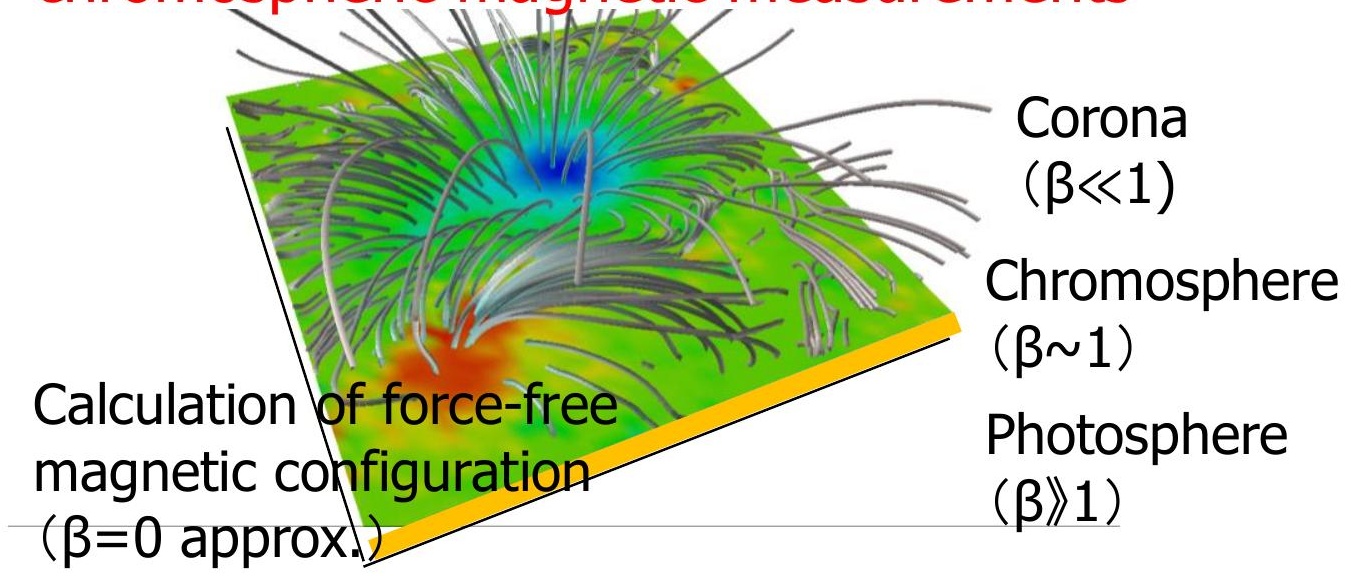




\section{Instrument Design}

Need a large aperture solar optical telescope, which provides high spatial resolution data of solar lower atmosphere from the photosphere to the uppermost chromosphere with enhanced spectroscopic and spectro-polarimetric capabilities covering a wide wavelength region from UV to near IR where many useful spectral lines and continua exist for physical diagnosis of the solar magnetized atmosphere.

Large-sized solar telescopes employ a Gregorian system because of the easiness of telescope thermal design which is crucially important for solar telescope.

In addition, the telescope is designed to fulfill the following scientific requirements:

(1) To resolve at least 0.1 arcsec solar magnetic features over a field view of $300 \times 300 \operatorname{arcsec}^{2}$

(2) to have a negligible chromatic aberration with a wide coverage of observation wavelengths from 280 to $1100 \mathrm{~nm}$ without frequent focus re-adjustment,

(3) To have a collimation optics making an exit pupil of about $40 \mathrm{~mm}$ diameter to accommodate clear apertures of image stabilization (TTM) and polarization modulation unit (PMU) and also to give a well-defined optical interface for aronmnanvino fonal nlane inctrumants and

(4) to give negligible instrum polarization measuremen

\section{- Constant PSF}

$\rightarrow$ High spatial resolution $\left(\sim 0.1^{\prime \prime}\right)$, Diffraction limited optics

$\rightarrow \quad$ High precision polarimetry $=\mathrm{dl} / \mathrm{I} \sim 10^{-4}$ in $10 \mathrm{sec}$ in NIR

1-m class aperture 
Conceptual Design of 1-m Aperture All-reflective Solar Telescope

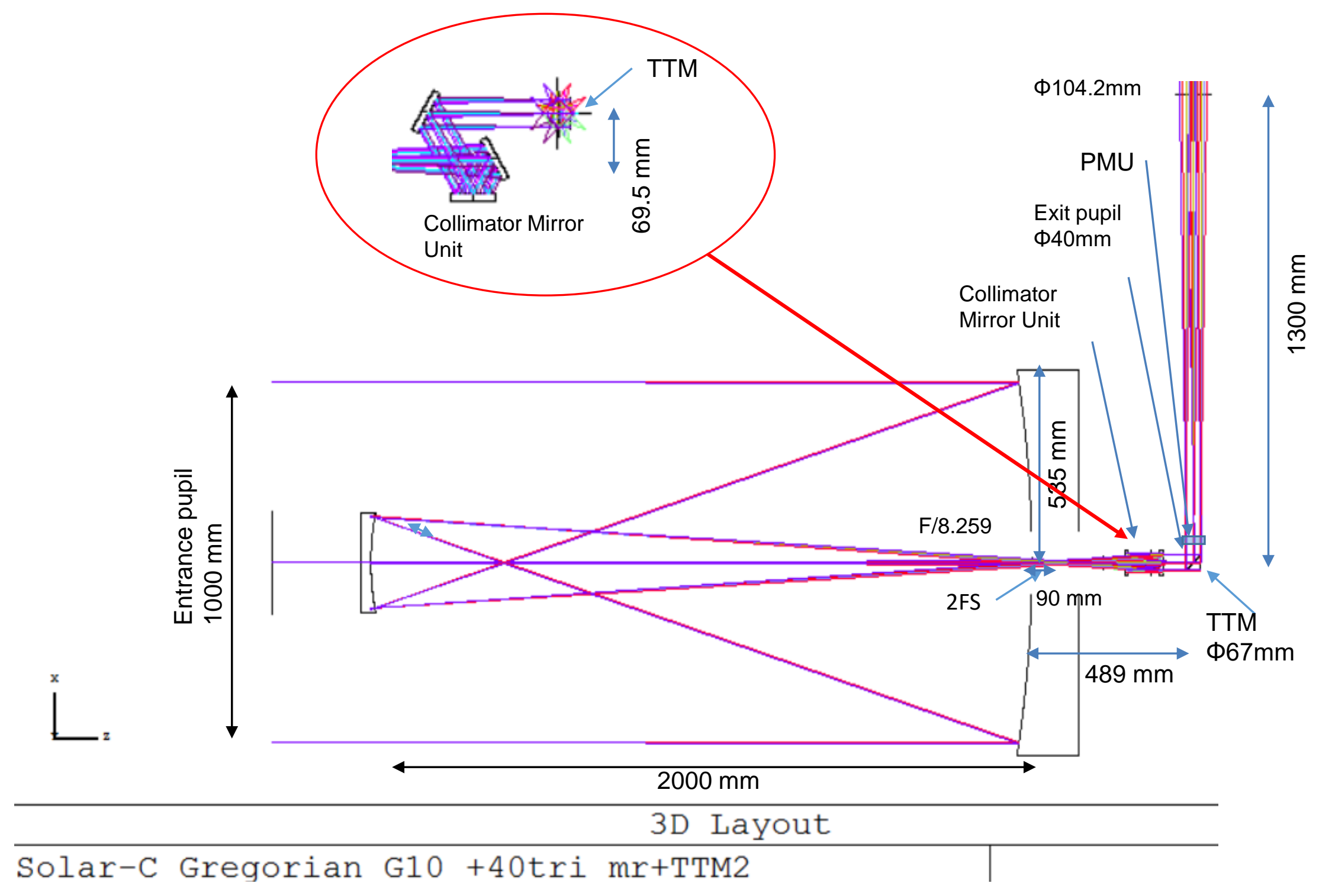




\section{$1^{\text {st }}$ step: Aplanatic Gregorian F/8.26}
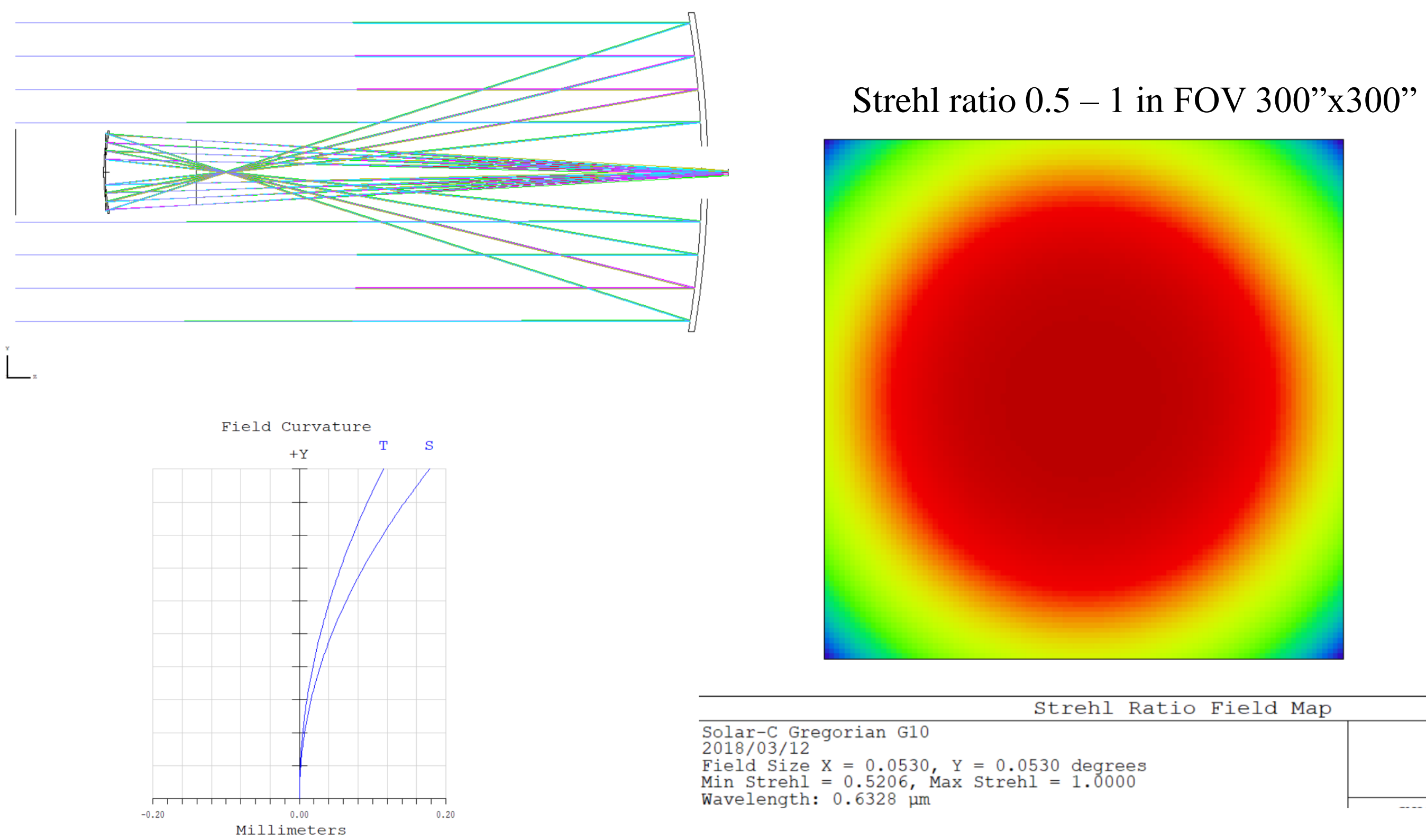

$1.00 \mathrm{E}+000$

$9.52 \mathrm{E}-001$

$9.04 \mathrm{E}-001$

$8.56 \mathrm{E}-001$

$8.08 \mathrm{E}-001$

$7.60 \mathrm{E}-001$

$7.12 \mathrm{E}-001$

$6.64 \mathrm{E}-001$

$6.16 \mathrm{E}-001$

$5.69 \mathrm{E}-001$

$5.21 \mathrm{E}-001$ 


\section{Design of Field Stops: HDM and 2FS}

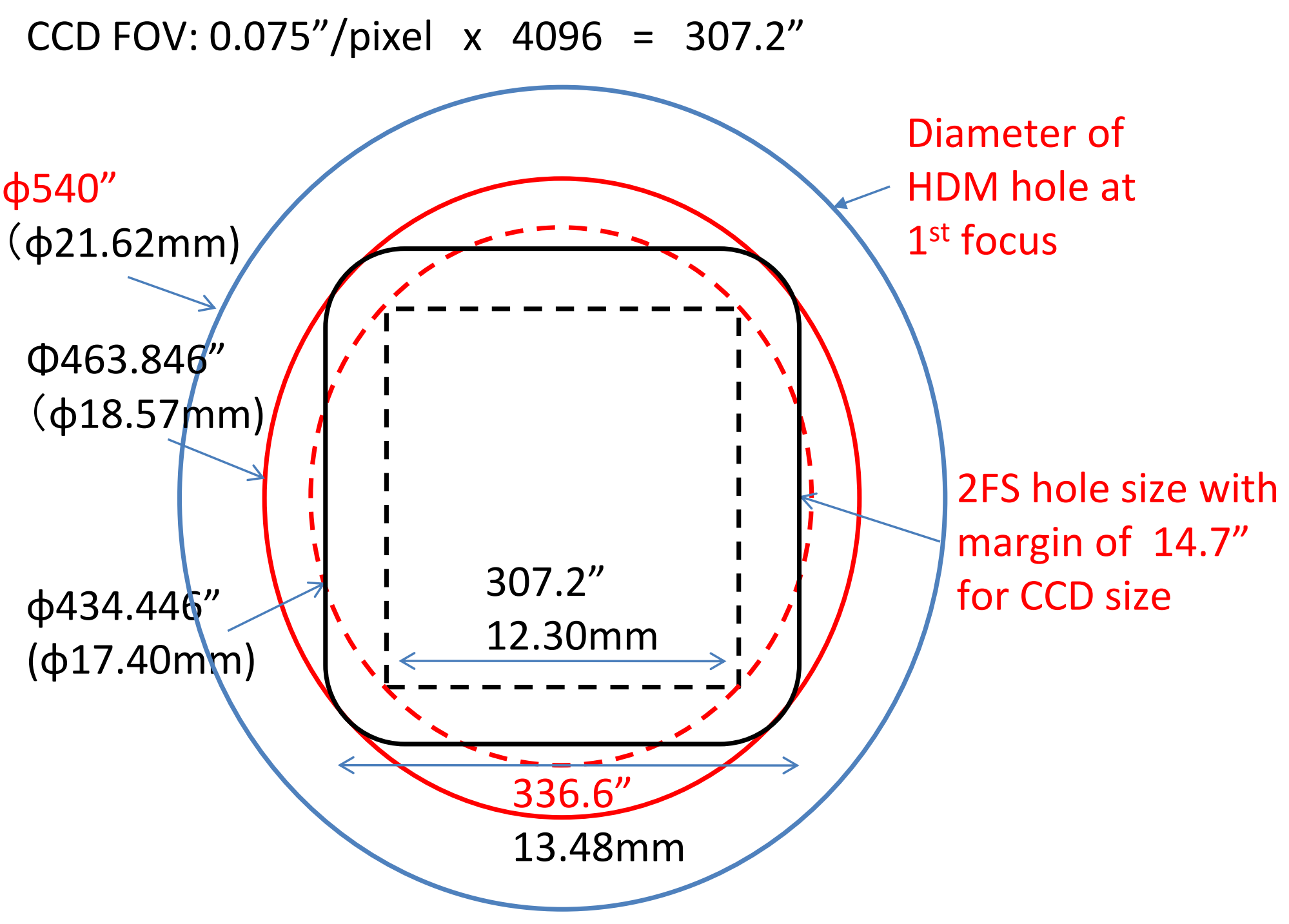




\section{Design of Gregorian Telescope with Two Heat Dump Mirrors: HDM and 2FS}

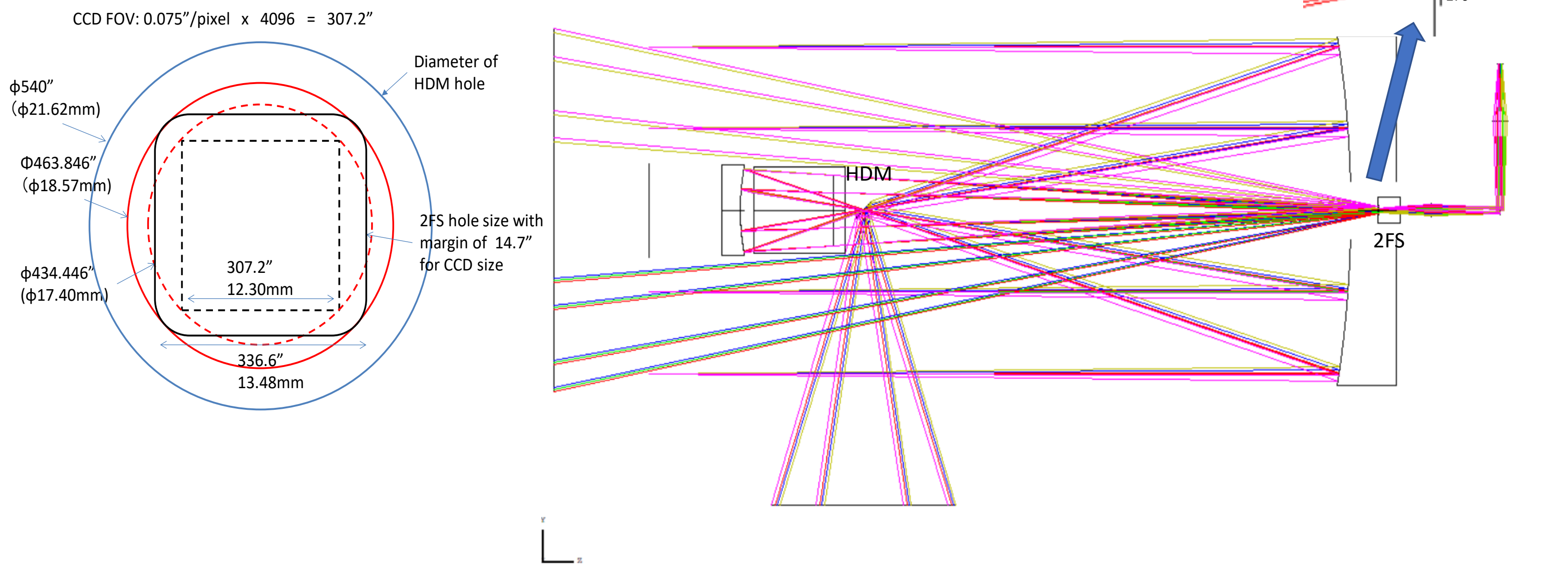




\section{$2^{\text {nd }}$ step: Design of Collimator Mirror Unit}
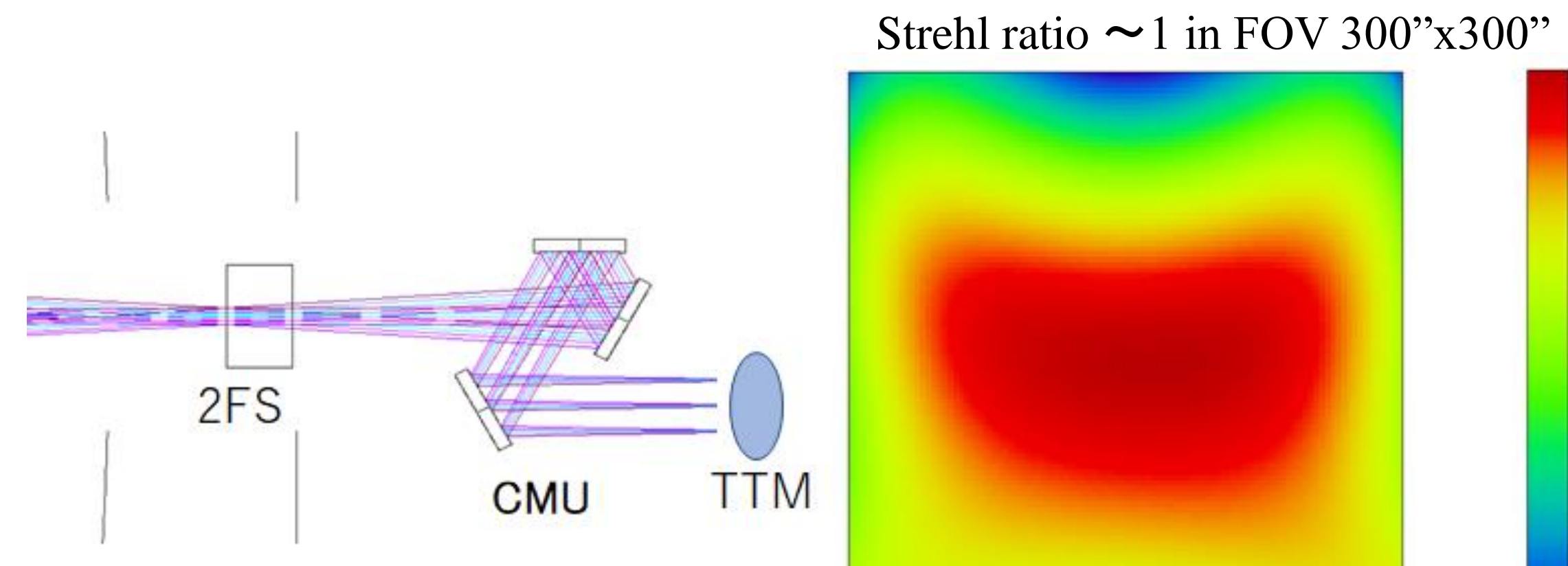

- To fulfill the achromatism over the wavelength from

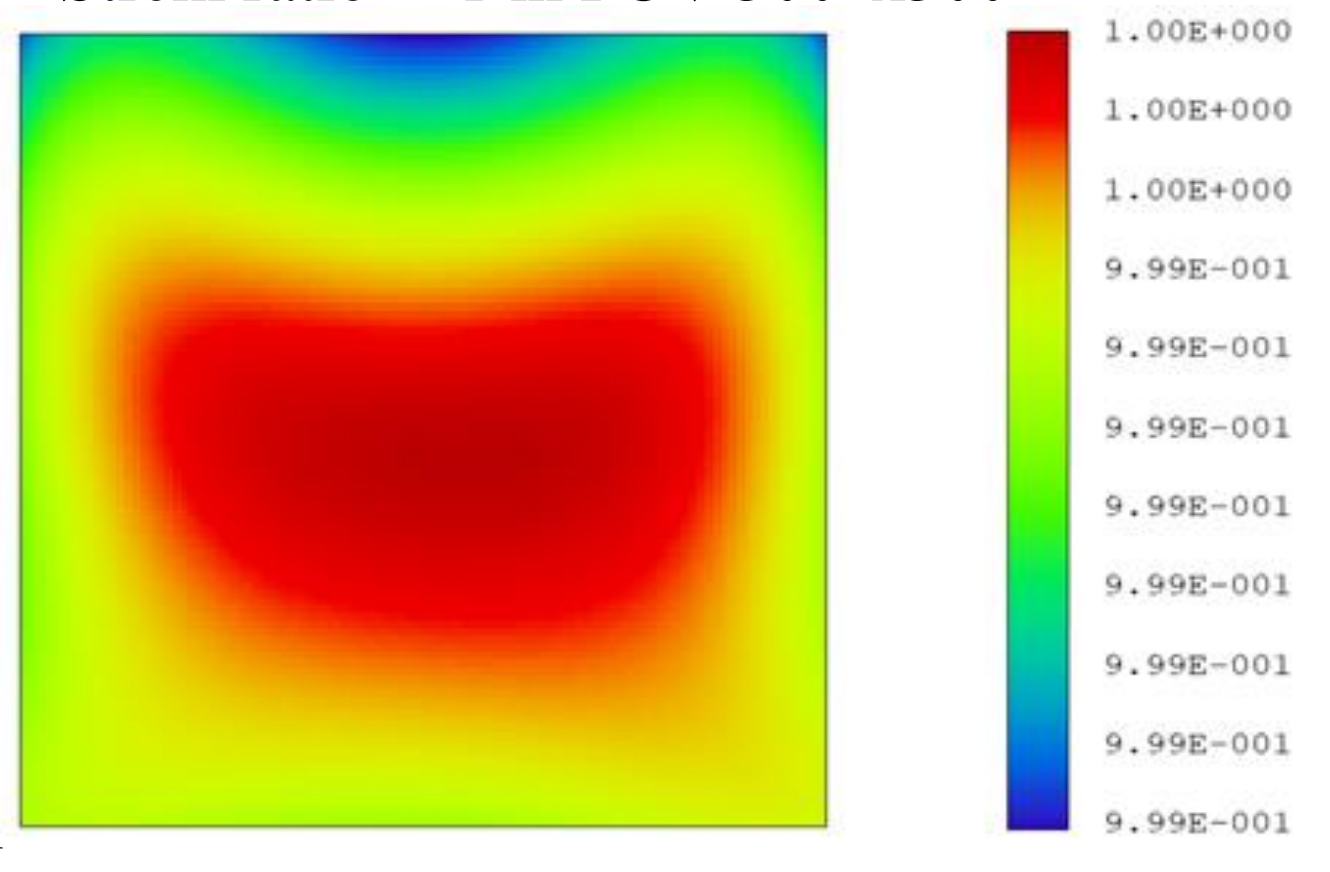
$280 \mathrm{~nm}$ to $1100 \mathrm{~nm}$, collimator unit was designed with allreflective system.

- On-axis three mirror systems which can accommodate the requirements of wide field performance, compactness in size. A design was found all three mirrors are on-axis aspherical; The surface figure expressed with Zernike first eleven terms, allowing spherically curved focus, readjusting the conic constants of M1 and M2 of the Gregorian.

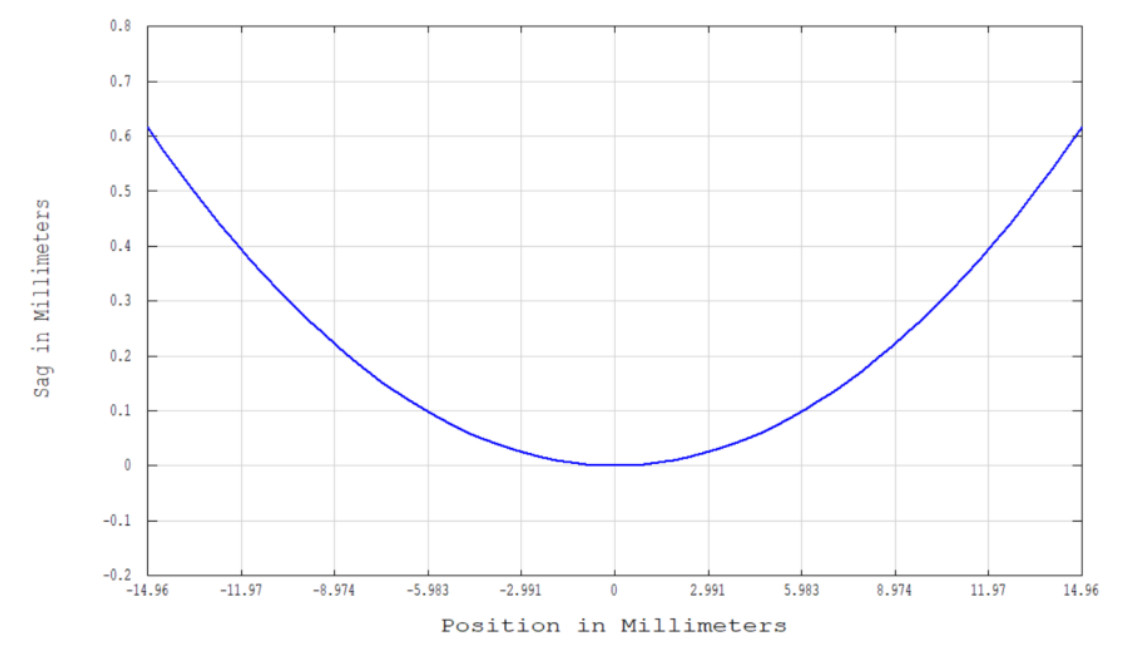

Field curvature 


\section{Silver coating: polarization pupil map}
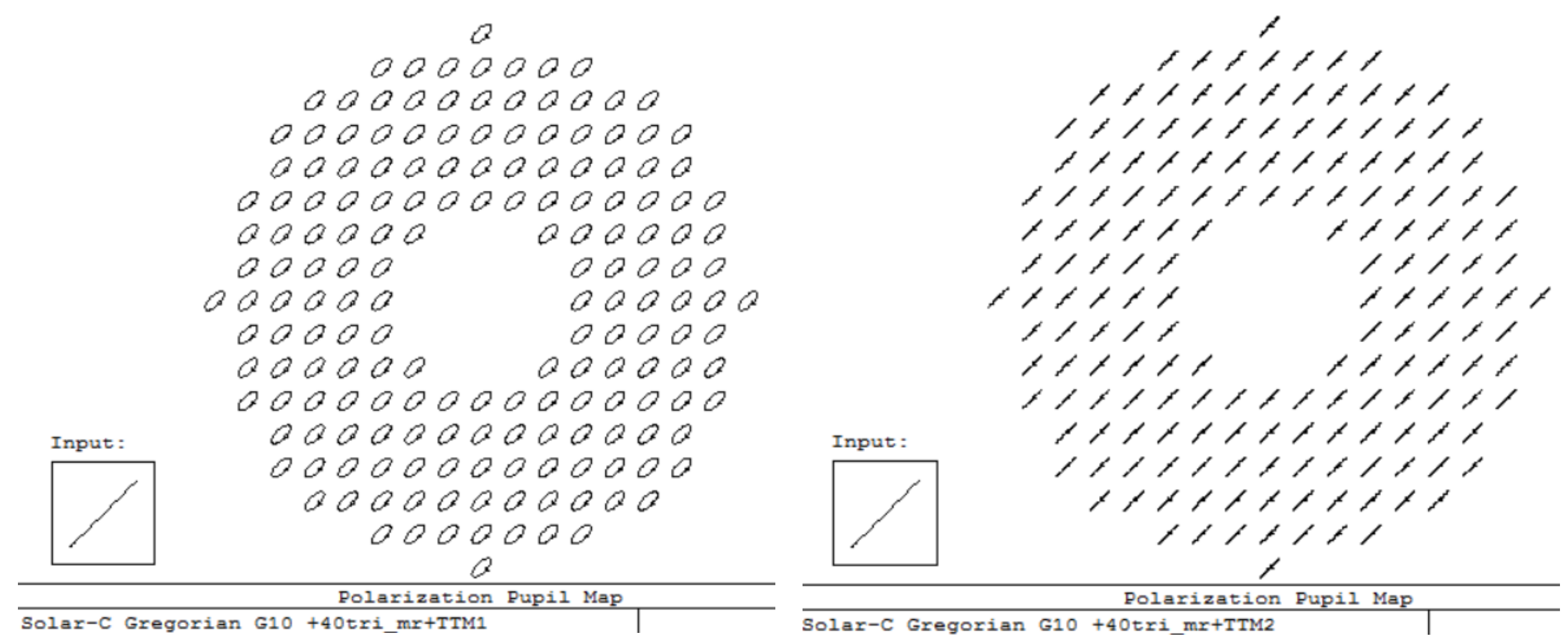


\section{$3^{\text {rd }}$ step: Design of Off-axis Ritchey-Chrétien Re-imager}

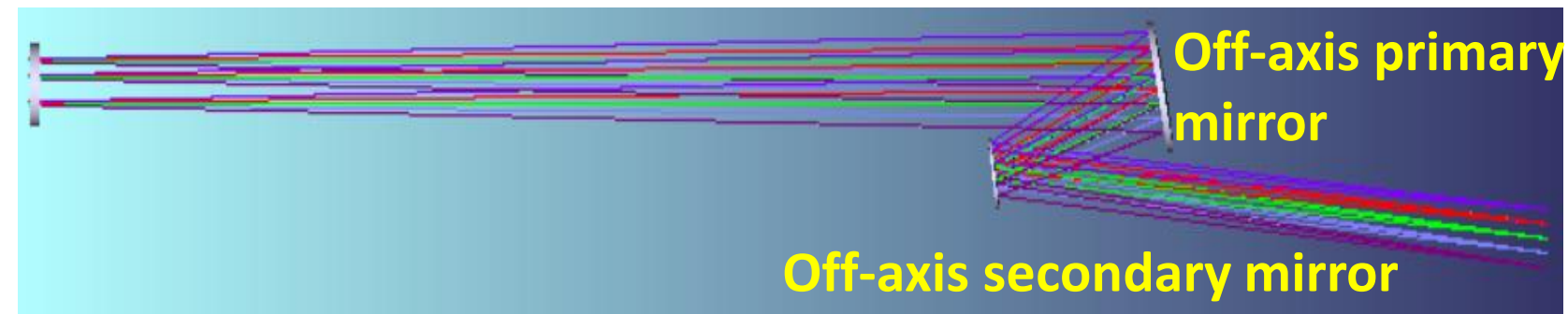

Strehl ratio 0.82- 1 in FOV 300"x300"

\section{Off-axis Ritchey-Chrétien}

- The field curvature caused by the Gregorian and CMU can be compensated by an off-axis Ritchey Chretien re-imaging optics which has an opposite sign in the field curvature to the Gregorian at an entrance of the focal plane instrument.

- Off-axis design was adopted to avoid any ray vignetting and to accommodate focusing mechanism.

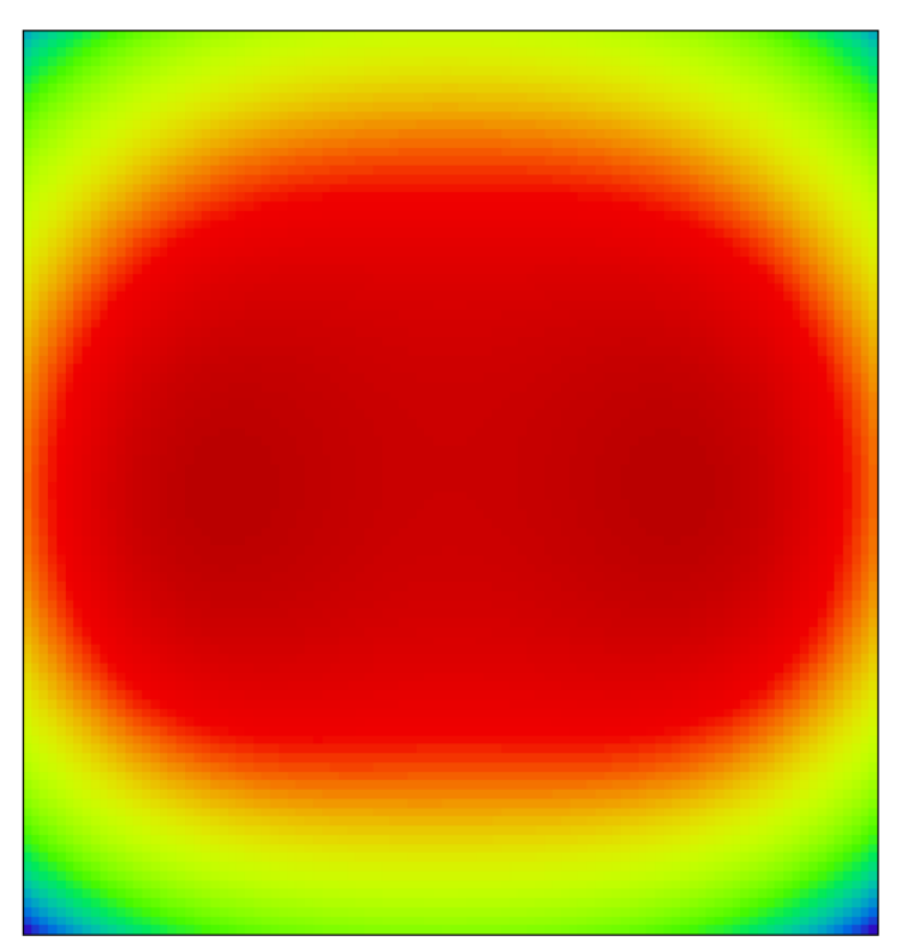




\section{Optical Parameters}

\begin{tabular}{|c|c|c|c|c|c|c|}
\hline Component & Mirror & $\begin{array}{l}\text { Clear } \\
\text { aperture } \\
(\mathrm{mm})\end{array}$ & $\begin{array}{l}\text { Radius of } \\
\text { Curvature } \\
(\mathrm{mm})\end{array}$ & Conic Const. & $\begin{array}{l}\text { Off-axis } \\
\text { distance } \\
\text { (mm) }\end{array}$ & $\begin{array}{l}\text { Aplanatic } \\
\text { Gregorian }\end{array}$ \\
\hline \multirow[t]{2}{*}{ Gregory } & M1 & 1004.6 & -3192.242 & -1.003465 & 0 & $k=-0.985$ \\
\hline & $\mathrm{M} 2$ & 254.8 & -676.9383 & -0.447949 & 0 & $k=-0.492$ \\
\hline \multirow[t]{3}{*}{ CMU } & M3 & 61.85 & -1649.919 & Zernike4-11 & 0 & \\
\hline & M4 & 63.49 & -1956.907 & Zernike4-11 & 0 & \\
\hline & M5 & 60.17 & -436.1516 & Zernike4-11 & 0 & \\
\hline TTM & M6 & 66.81 & infinity & 0 & 0 & \\
\hline PMU & & 45.2 & & & & \\
\hline \multirow{2}{*}{$\begin{array}{l}\text { Ritchey- } \\
\text { Chrétien Re- } \\
\text { imager }\end{array}$} & M7 & 96 & -637.7692 & -1.088166 & 129.7 & \\
\hline & M8 & 54 & +365.8725 & -3.142539 & 57.5 & \\
\hline
\end{tabular}




\section{Optical Performance in UV to NIR}

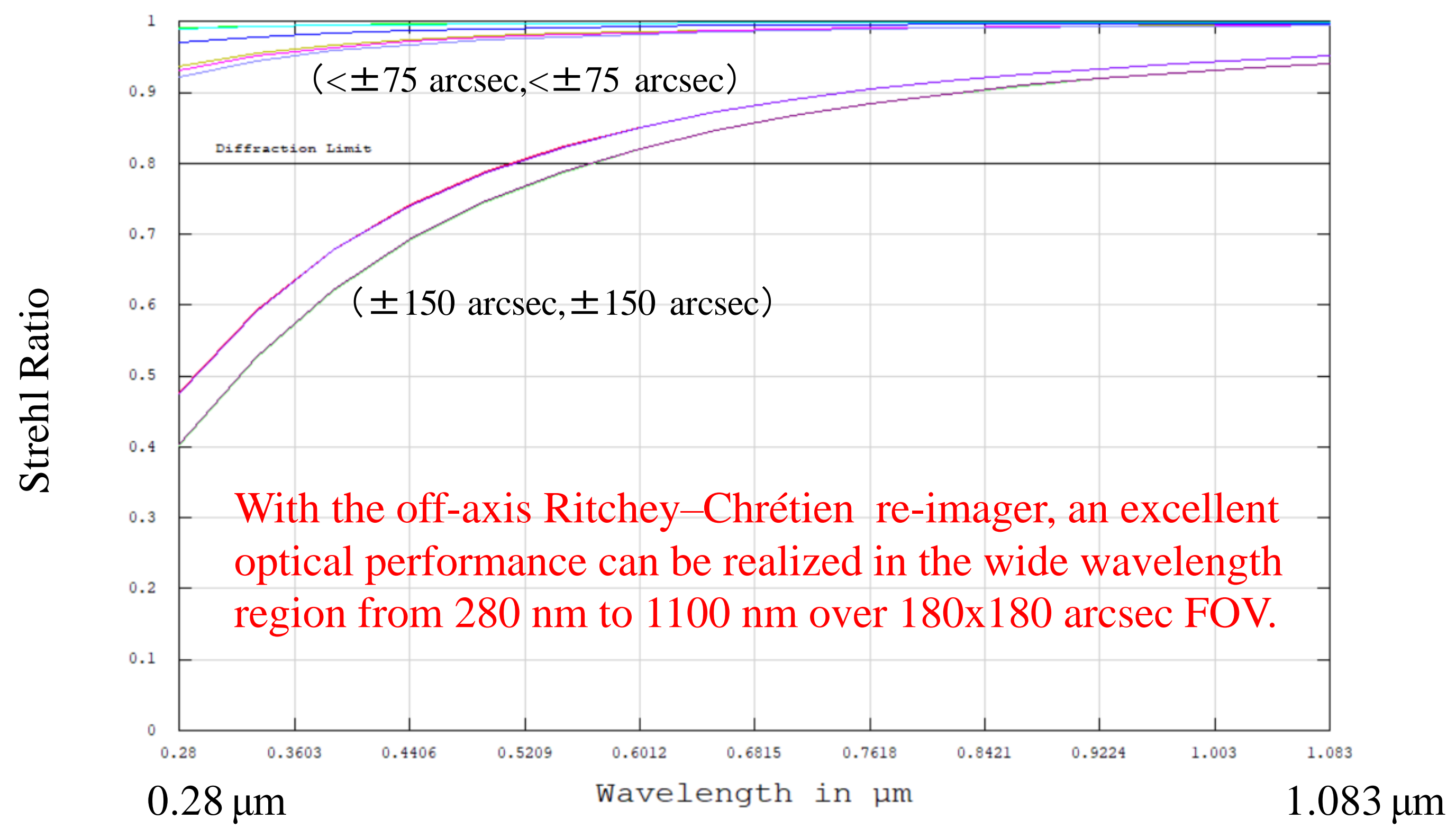




\section{Optical Layout of Telescope to Re-imager}

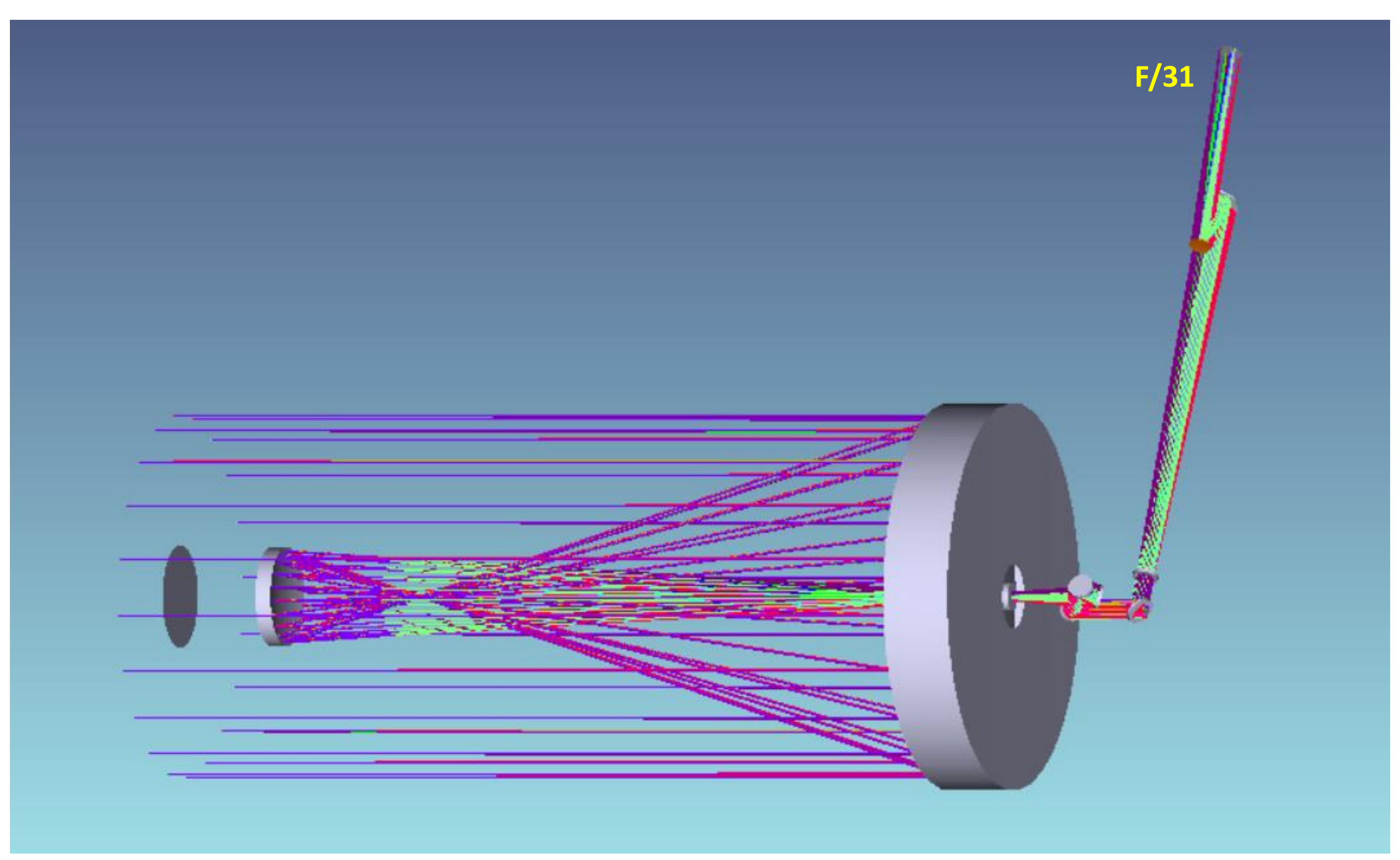


Solar light input and resulted absorbed energy by telescope optical components in the case of begin of life (BOL) and end of life (EOL). In EOL, solar light absorption by mirrors are assumed to be incremented by $5 \%$ for each coating.

\begin{tabular}{|c|c|c|c|c|}
\hline & \multicolumn{2}{|c|}{ BOL } & \multicolumn{2}{|c|}{ EOL } \\
\hline Component (coating) & Input (W) & Absorption (W) & Input (W) & Absorption (W) \\
\hline M1 (protected Ag) & 948.668 & 64.5 & 948.668 & 111.943 \\
\hline M2(protected Ag) & 67.456 & 4.59 & 63.84 & 7.53 \\
\hline HDM (enhanced Ag) & 816.7 & 40.84 & 772.89 & 77.29 \\
\hline 2FS (enhanced Ag) & 31.82 & 1.59 & 28.5 & 2.85 \\
\hline CMU (enhanced Ag) & 31.05 & 4.42 & 27.81 & 7.54 \\
\hline TTM (enhanced Ag) & 31.05 & 1.55 & 27.78 & 2.78 \\
\hline PMU (alpha=0.0075) & 29.5 & 0.22 & 25 & 0.18 \\
\hline Re-imager & 29.3 & 1.46 & 24.8 & 2.53 \\
\hline
\end{tabular}


Obs

wavelength
Mirror Coating Development

\author{
Mg II h\&k
}

280nm
G-band

430nm
$\mathrm{Na}$ I D

$589 \mathrm{~nm}$

$656 \mathrm{~nm}$
Ca II IR

$854 \mathrm{~nm}$
$\mathrm{He} I$

$1083 \mathrm{~nm}$

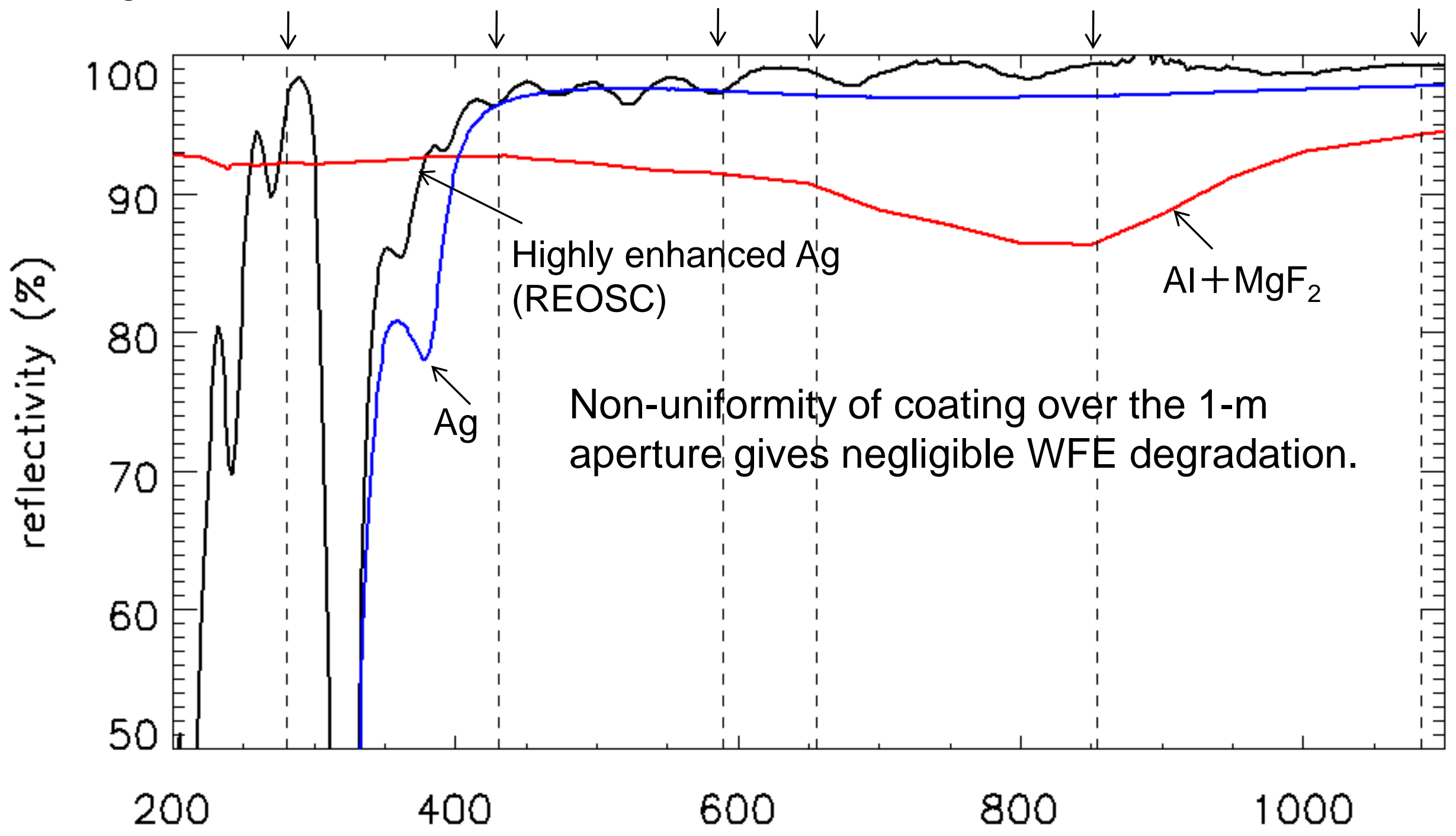

wavelength $(\mathrm{nm})$ 


\section{Structure Design of Telescope}

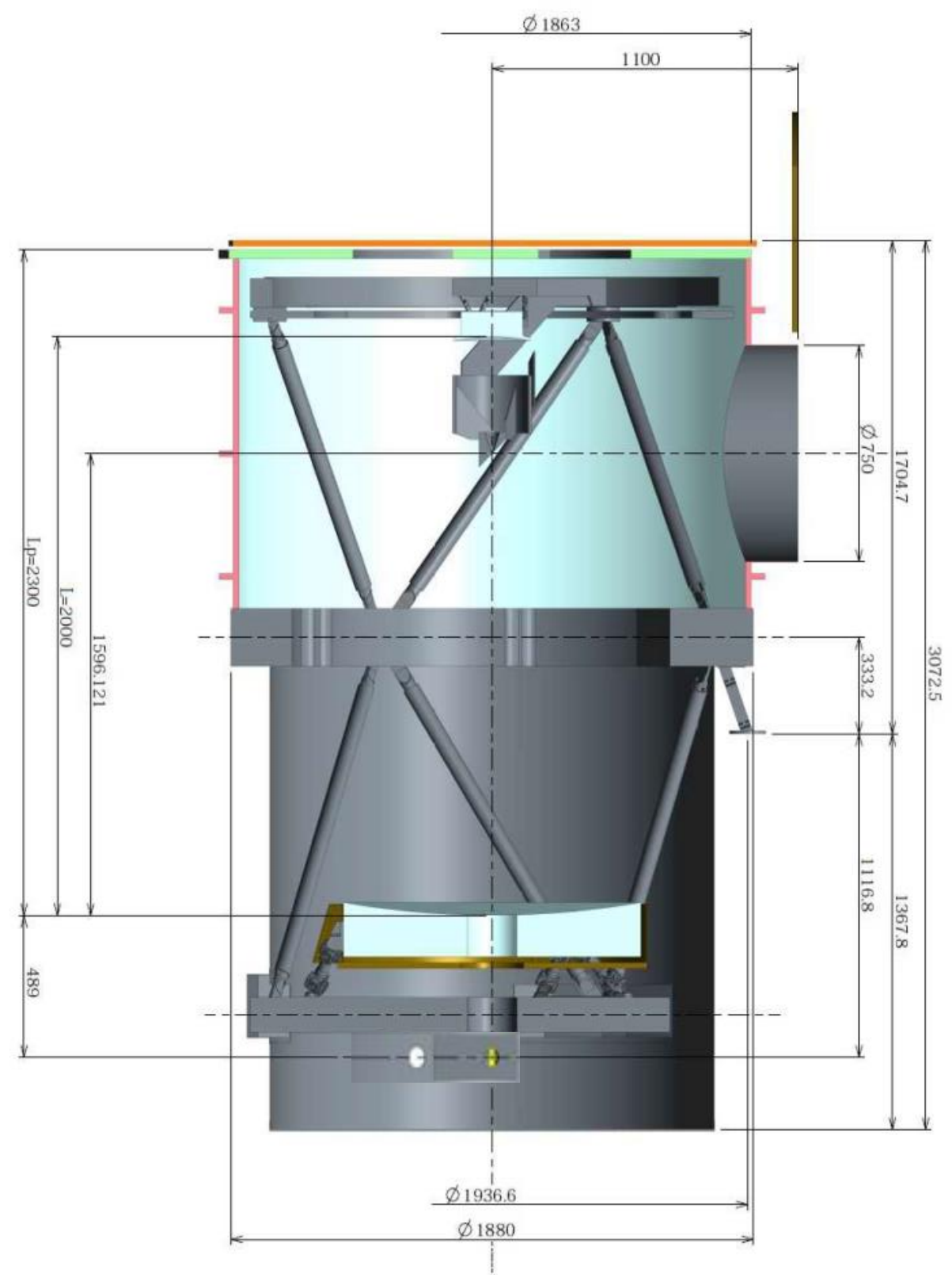

$\sqrt{T 6} 6.5$
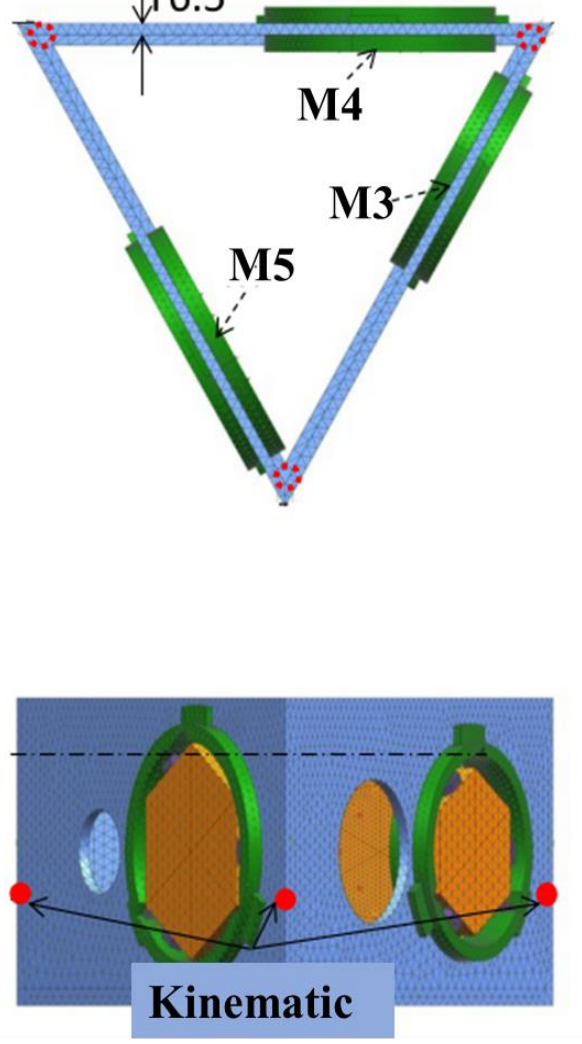


\section{Thermal Design of Telescope}

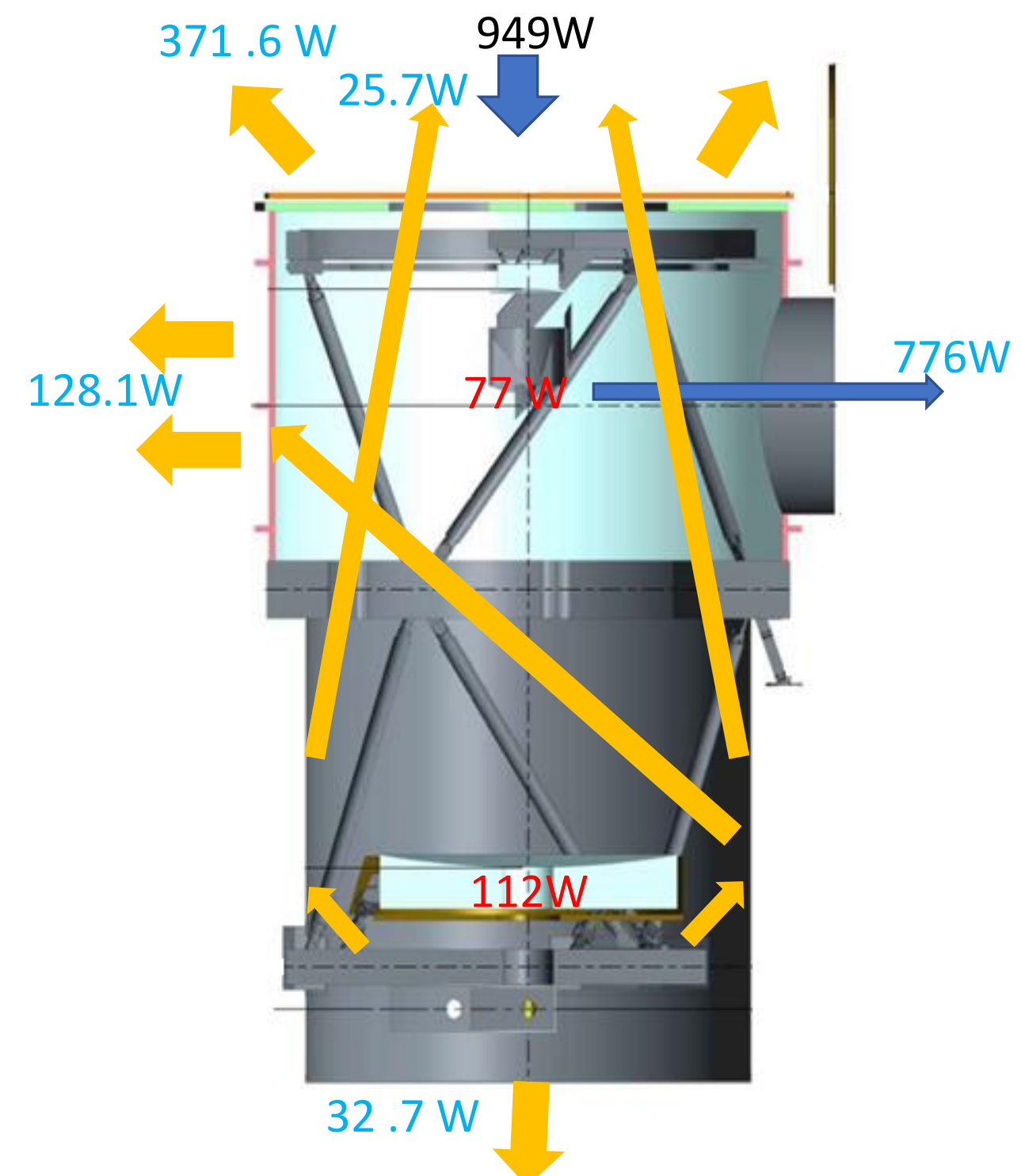

- Most incident energy coming inside the telescope is reflected back by the primary mirror M1 and dumped out to space by the HDM at the primary focus through the heat dump window.

- Solar heat absorbed by the M1 is radiatively transmitted to a telescope lower tube from its side and from a bottom cooling plate just beneath the M1 which radiatively absorbs the heat of the mirror from its back face.

- A sunshade and upper half of the telescope upper tube work as a thermal radiator.

- The heat of the lower tube and the upper tube is radiatively emitted directly to the $3 \mathrm{~K}$ temperature of space through the entrance pupil and indirectly via the radiator of the sunshade and upper tube.

- A design was found that the temperature of M1 and entire structure can be maintained close to the room temperature with reasonable radiator area. 
The significant surface error of the M1 mirror is caused by the difference of CTE between the pads and the mirror substrate. M1 thermal deformation is very sensitive and its temperature need to be controlled close to a room temperature.

\begin{tabular}{|l|r|r|}
\hline Component & $\begin{array}{l}\text { Absorption } \\
(\mathrm{W}) \text { in EOL }\end{array}$ & $\begin{array}{l}\text { Predicted } \\
\text { Temperature } \\
\left({ }^{\circ} \mathrm{C}\right)\end{array}$ \\
\hline M1 & 111.943 & $11 \sim 46$ \\
\hline M2 & 7.53 & -30 \\
\hline HDM & 77.29 & 26 \\
\hline 2 FS & 2.85 & 4 \\
\hline CMU & 7.54 & 16 \\
\hline TTM & 2.78 & 10 \\
\hline
\end{tabular}

Remarks: Solar Input $1421 \mathrm{~W} / \mathrm{m} 2$

P-Ag: Protected Silver Coating,

E-Ag: Enhanced Silver Coating

PMU is assumed to absorb light $\lambda \geqq 4 \mu \mathrm{m}$, no change in $\mathrm{BOL}$ and $\mathrm{EOL}$

Electric powers of PMU and TTM are neglected
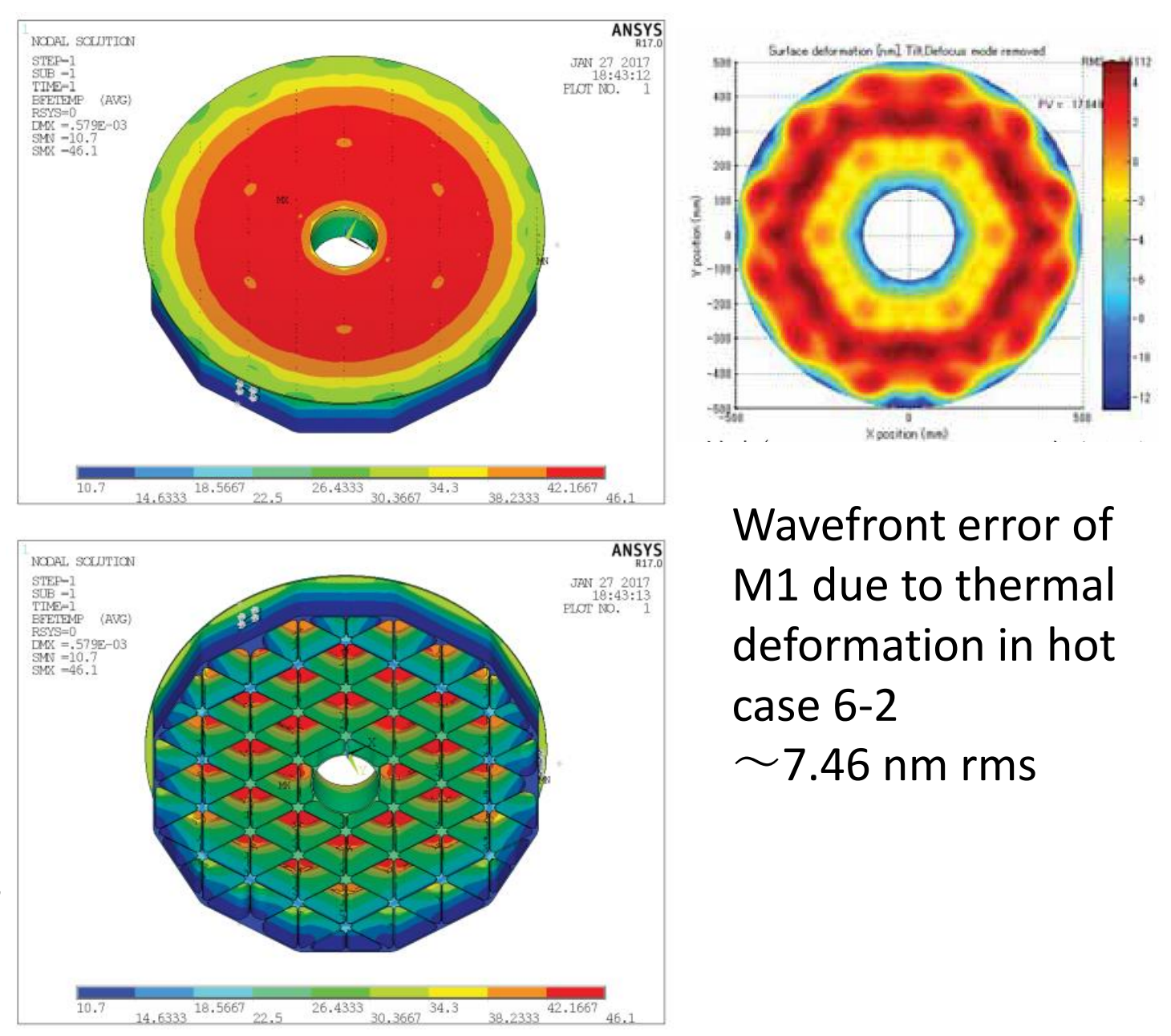

Wavefront error of M1 due to thermal deformation in hot case 6-2

$\sim 7.46 \mathrm{~nm} \mathrm{rms}$

Temperature distribution of M1 in hot case 6-2 


\section{Summary}

We designed an all-reflective 1-m aperture optical telescope to fulfill the scientific and engineering requirements:

(1) to resolve 0.1 arcsec solar features over a field-of-view of 300x300 arcsec,

(2) to realize chromatic aberration free optics for observing wavelength range from UV to near IR,

(3) to give a collimated optical interface with a following focal plane instrument, placing moving optical component like a rotating polarization modulator and a tip-tilt image stabilization folding mirror around an exit pupil of diameter about $40 \mathrm{~mm}$,

(4) to give negligible instrumental polarization before a polarization modulator for precise polarization measurements, and

(5) to accommodate thermal design to reject unwanted solar light from the telescope components as early as possible.

- A design of a compact tri-aspheric-mirror collimator is a key and innovative for large aperture solar optical telescope of diffraction-limited performance over large field-of-view. The filed curvature remained is compensated by a Ritchey Chretien reimaging optics which has an opposite sign in the field curvature.

- Thus all-reflective solar optical telescope of high optical performance over a large field of view can be designed for space solar mission.

- Based on a geosynchronous orbit and a thermal model of passive control design, the temperature of M1 pads can be controlled close to a room temperature which cause less thermal deformation. 
Thank you for your attention 